\title{
Numerical Simulation of Initiation of Rainfall-Induced Debris Flow
}

\author{
Shuyun Wang, Xiaobing Lu, and Tianli Ye
}

\begin{abstract}
Two-phase flow model, modified Mohr-Coulomb model and the theory of unsaturated soil are adopt in FLAC, and then the characteristics of seepage flow of Beichuan soil under rainfall conditions are numerically simulated. It is shown that the initiation of rainfall-induced debris flow is affected by rainfall density and duration. The maximum horizontal displacement occurs at the foot of the slope and increases with rainfall duration. The vertical displacement is nonuniform and the maximum value occurs at point $\mathrm{A}$, which is at the top of two-third. Whether or not a sudden change of displacement occurs at the characteristic point $\mathrm{A}$ is suggested to judge if debris flow starts. It is also shown there is a good agreement between numerical simulation results and rainfall model test data in laboratory.
\end{abstract}

\section{Keywords}

Debris flow • Rainfall - Initiation - Unsaturated soil • Simulation

\subsection{Introduction}

Rainfall is one of the main factors that can trigger debris flow. At present, many achievements (Liu 1998; Yao et al. 2001; Xie and Xu 1999; Lio and Yan 1995; Xu and Yang 2000; Gong et al. 2002) on the study of unsaturated soil strength have been reported, and some theory frames based on the deformation of unsaturated soil have been made on the study of rainfall-induced debris flow (Richards 1931; Iverson et al. 1997; Iverson 1997; Iverson 1989; Major and Iverson 1999; Qin and Huang 2003; Chen and Sun 2007). Chen (1997) used limit equilibrium method and proposed an analysis method to estimate the stability of unsaturated soil slope. Li and Zhang (2001) set up a distribution equation of water volumetric content in transient state during rainfall and seepage. Zhu and Liu (2002) applied finite element method to a constitute relationship of saturated-unsaturated soil and

S. Wang $(\bowtie) \cdot X . \mathrm{Lu} \cdot$ T. Ye

Key Laboratory for Mechanics in Fluid Solid Coupling Systems, Institute of Mechanics, Chinese Academy of Sciences, Beijing 10019, China

e-mail: sywang@imech.ac.cn made a non-liner elastic model. Sun et al. (1997, 1995) performed a comparing simulation of slope stability in onephase flow model with those in two-phase flow model. Generally, the former studies indicate that the theory of unsaturated soil has been widely accepted in the analyses of slope stability.

In this study, the model of two-phase fluid in FLAC is adopted and the displacement of soil is numerically simulated under different rainfall density and duration. It is proposed that a sudden change of displacement at the characteristic point can be used as a criterion to judge the initiation of debris flow.

\subsection{Model and Conditions}

The element mesh in finite difference method is divided and shown in Fig. 75.1a, and the rainfall model test in laboratory is shown in Fig. 75.1b. Point A is two-third far from the top of slope and has the maximum vertical displacement which has been identified by the following numerical simulation.

The modified Mohr-Coulomb model is adopted and the parameters of soil are as follows: dry density $5.8 \mathrm{kN} / \mathrm{m}^{3}$, effective cohesion $20 \mathrm{kPa}$, friction angle $30^{\circ}$, volume 


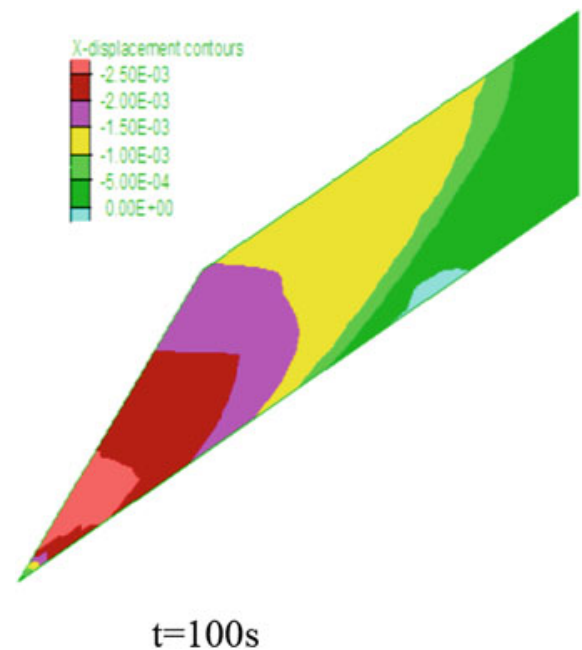

Fig. 75.1 Element mesh for numerical simulation and a sketch of corresponding rainfall model test in laboratory. a Element mesh. (b) Sketch of model test
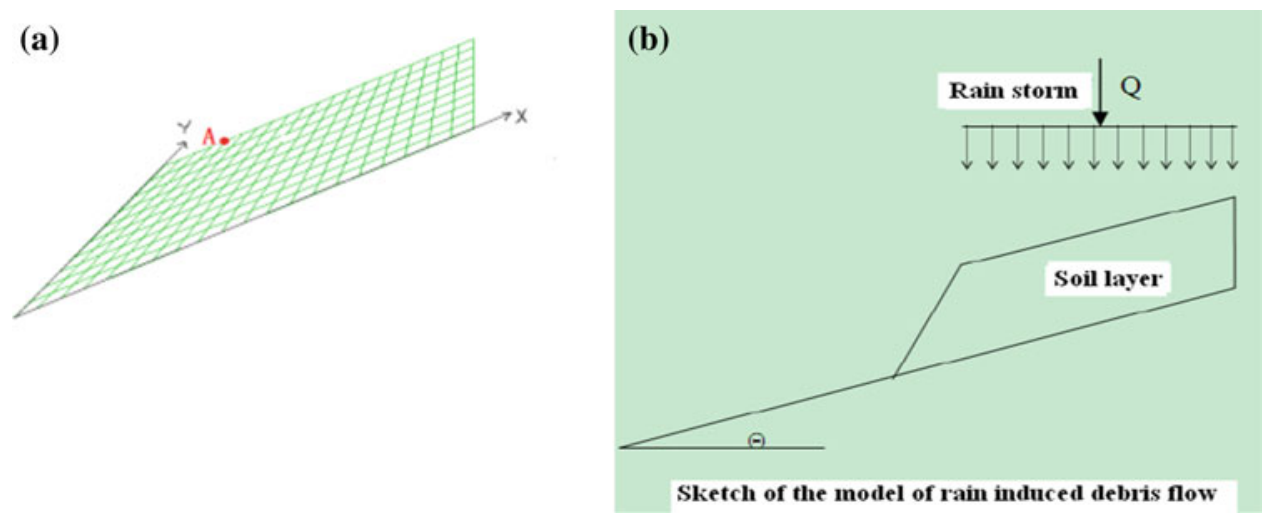

Fig. 75.2 Distribution of horizontal displacement when $\mathrm{t}=100 \mathrm{~s}$ and $\mathrm{t}=400 \mathrm{~s}$ modulus $0.8 \mathrm{GPa}$, shear modulus $0.6 \mathrm{GPa}$, saturated permeability $1.0 \times 10^{-5}$, initial saturation 0.5 . The rainfall density is chose as $1 \times 10^{-5}, 2 \times 10^{-5}, 3 \times 10^{-5}, 4 \times 10^{-5}$ and $5 \times 10^{-5} \mathrm{~m} / \mathrm{s}$. The angle of soil slope is chose as $27^{\circ}, 30^{\circ}$ and $33^{\circ}$ respectively.

\subsection{Results and Discussions}

\subsubsection{Displacement of Soil}

Figures 75.2 and 75.3 shows the horizontal and vertical displacements with rainfall duration when rainfall density is $1 \times 10^{-5} \mathrm{~m} / \mathrm{s}$ and the angle of slope is $27^{\circ}$.

The horizontal displacement is smaller at the beginning of rainfall and the maximum displacement occurs at the foot of slope, the soil on the left side of the slope has the maximum horizontal displacement. These maximum displacement values form a potential slide zone. The vertical displacement in the upper layer of soil is much bigger than the lower layer of soil. The maximum vertical displacement occurs on the surface of soil, and the maximum point finally reaches to the position of two-third of slope.
By combining the horizontal displacement with the vertical ones, it is concluded that the differential settlement of soil is reduced mainly by the horizontal displacement. The left of soil continues to slide down with the rainfall duration while the total volume of soil is a constant. Due to the differential behavior and the increase of maximum value of vertical displacement, the soil at this point will be dislocated with the above soil and then form a slide zone and trigger debris flow.

\subsubsection{Velocity Vector of Soil}

Figure 75.4 shows the distribution of velocity vector. At the beginning of rainfall, the increment rate of velocity is smaller, but with the increase of rainfall duration, this increment becomes bigger and bigger. The maximum velocity vector component in horizontal direction occurs at the foot of slope, the maximum value in vertical direction occurs at the point of two-third of slope from the top of the slope, and that is consistent with the analyses results about maximum displacement. On the whole slope, the vertical component is obviously smaller than the horizontal ones. 
Fig. 75.3 Distribution of vertical displacement when $\mathrm{t}=100 \mathrm{~s}$ and $\mathrm{t}=400 \mathrm{~s}$

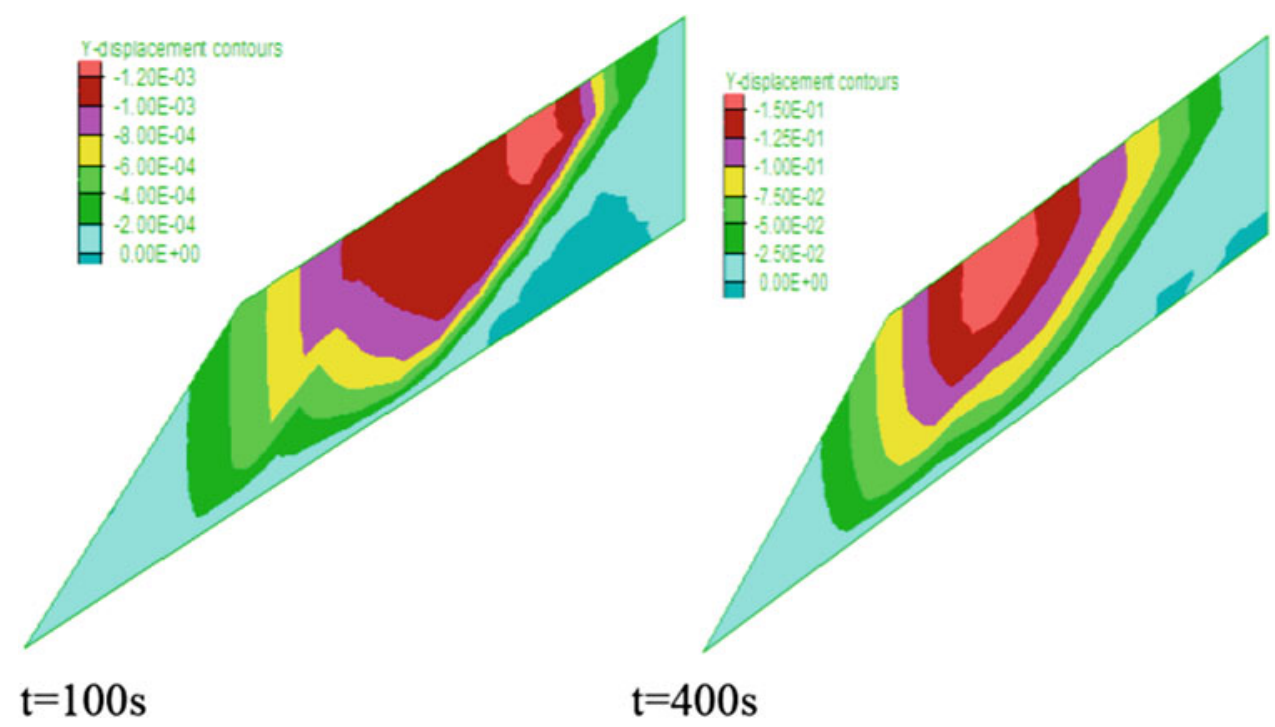

Fig. 75.4 Distribution of velocity vector when $\mathrm{t}=100 \mathrm{~s}$ and $\mathrm{t}=400 \mathrm{~s}$

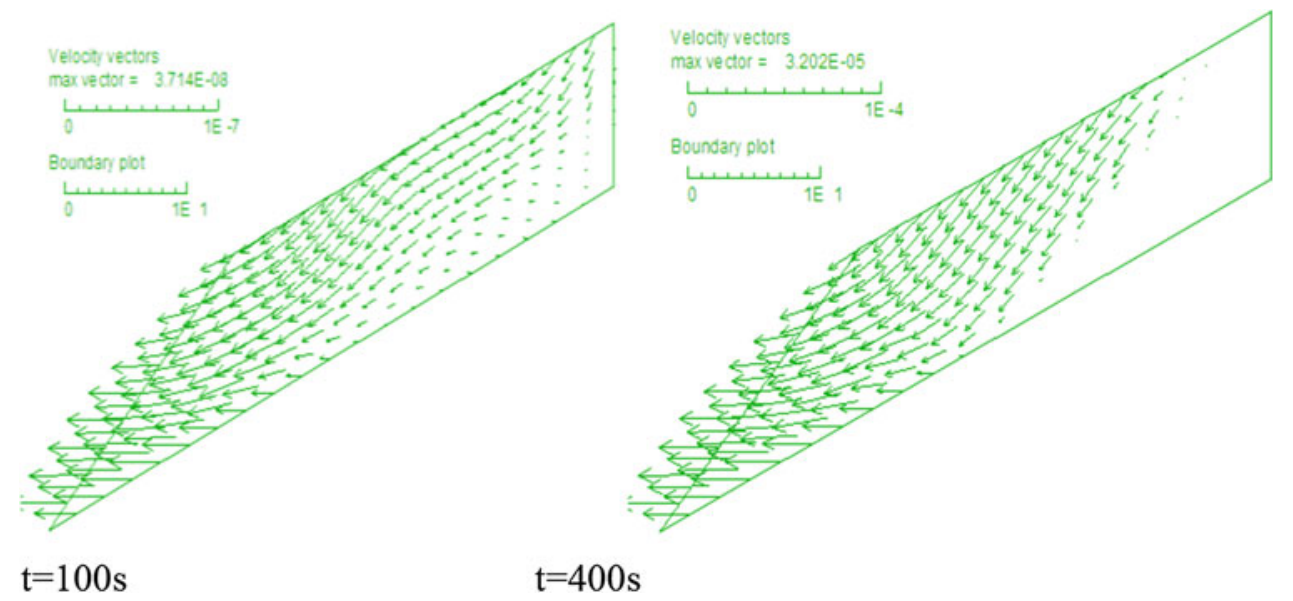

That is to say, the horizontal movement of soil plays a leading role. It is also observed that the area of soil having bigger movement gradually decreases and inclines to move to the left side of the slope with the increase of rainfall duration.

Figure 75.5 shows that the maximum velocity vector increases with the rainfall duration. The maximum velocity vector has a bigger increase when the rainfall time is longer than $200 \mathrm{~s}$.

\subsubsection{Initiation of Debris Flow}

Figure 75.6 shows that the maximum displacement increases with the rainfall duration and its maximum value is smaller at the beginning of rainfall under all rainfall density. But the maximum displacement has a sudden change after a period of time. When the angle of slope is a constant $\left(27^{\circ}\right)$, this sudden change occurs in a shorter time with the increase of rainfall density. This phenomenon is also verified when the

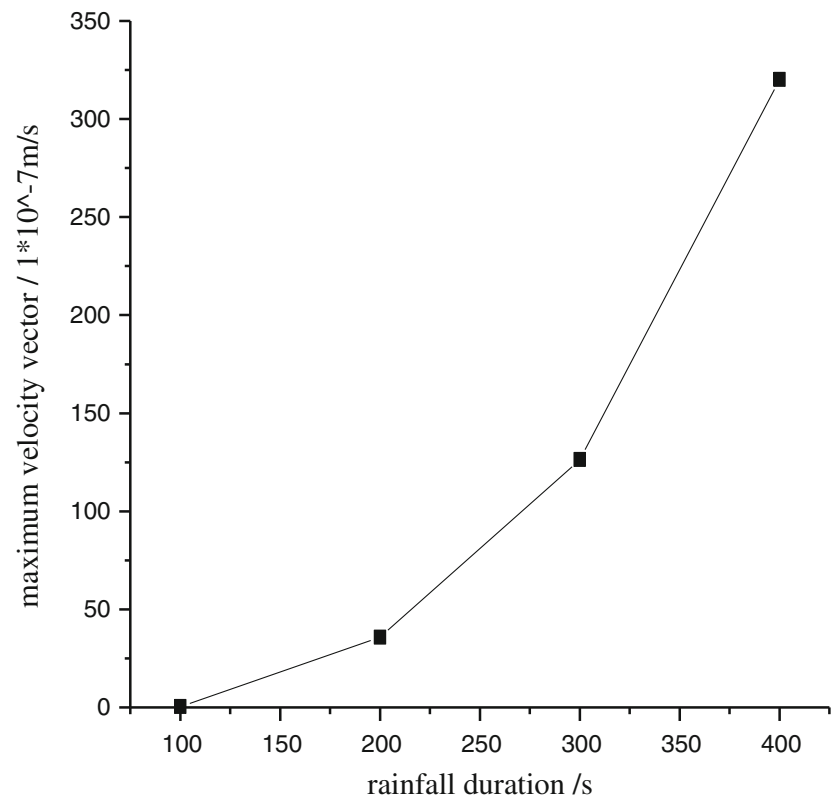

Fig. 75.5 The maximum velocity vector versus the rainfall duration 

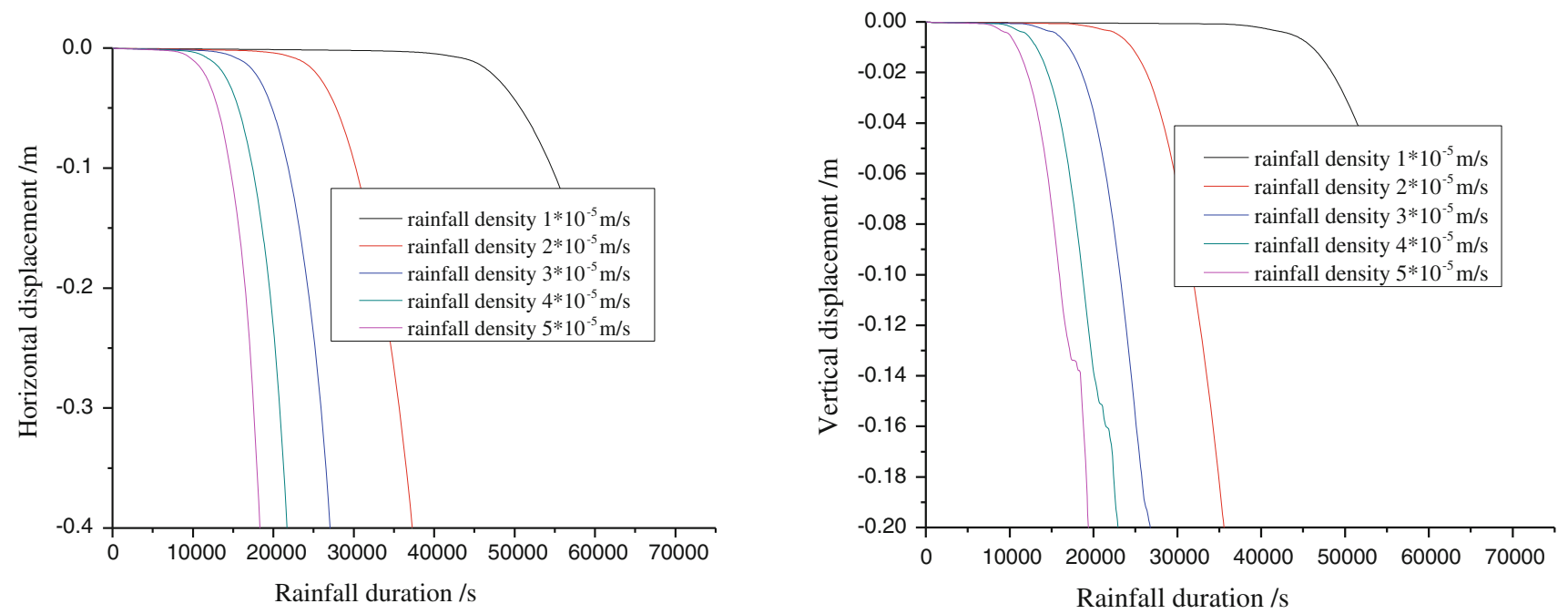

Fig. 75.6 Maximum horizontal and vertical displacement under different rainfall density
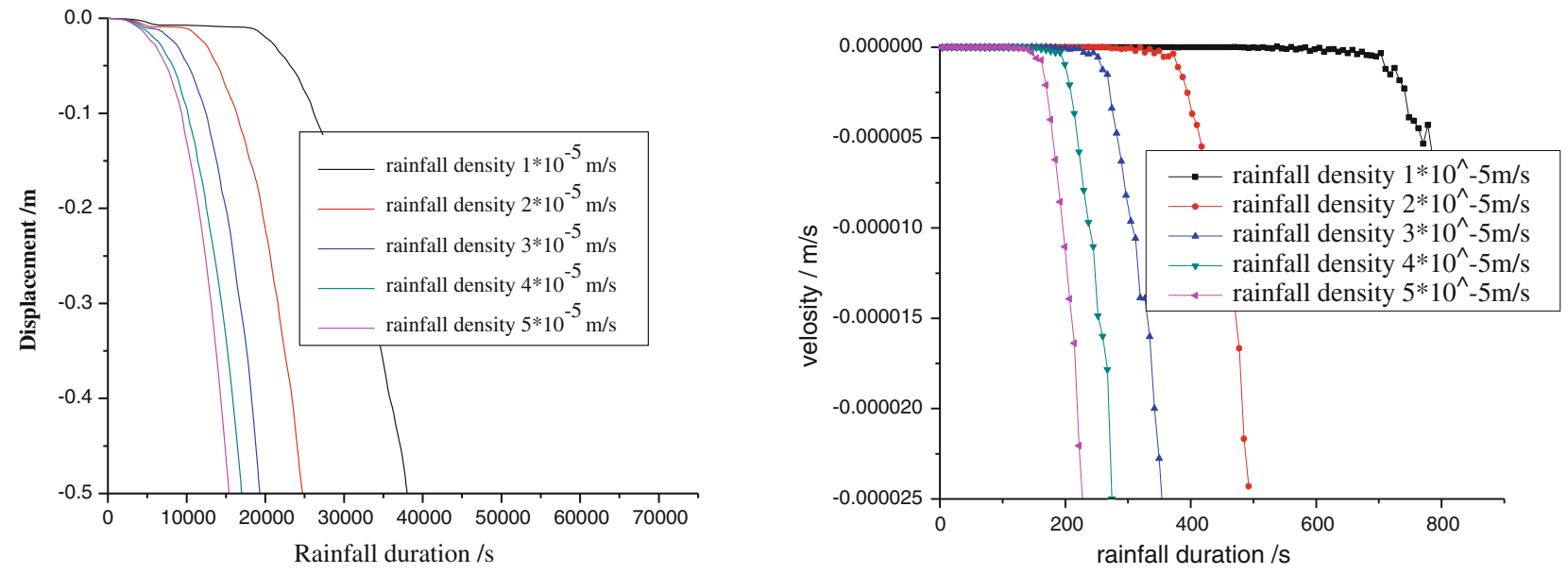

Fig. 75.7 Horizontal displacement and horizontal velocity at point A under different rainfall density

angle of slope is $30^{\circ}$ and $33^{\circ}$. Because the maximum of vertical displacement occurs at a point of two-third of the slope from the top of the slope, and this point is also the intersection point between the soil sliding band and the surface of slope. Therefore, point A shown in Fig. 75.1 is thought as a characteristic point.

Figure 75.7 shows that the smaller the density of rainfall is, the longer the initiating time needed by debris flow. Under the same rainfall density, the bigger the angle of slope, the shorter the initiating time of debris flow. This phenomenon is very consistent with that from laboratory model test. When the rainfall lasts a period of time, the velocity suddenly changes. The trend of horizontal velocity versus time is the same as that of horizontal displacement at point A. Moreover, the sudden changed velocity needs time shorter than that of displacement.

As Fig. 75.8 shown, the initiation time of debris flow with the rainfall duration obtained by the simulation is the same as that obtained from rainfall model test data in laboratory, which is mentioned above. When the angle of slope is constant and the rainfall density is smaller, the initiating time will be longer. With the increase of rainfall density, the initiating time will be shorter, and the increment rate of time is bigger. 


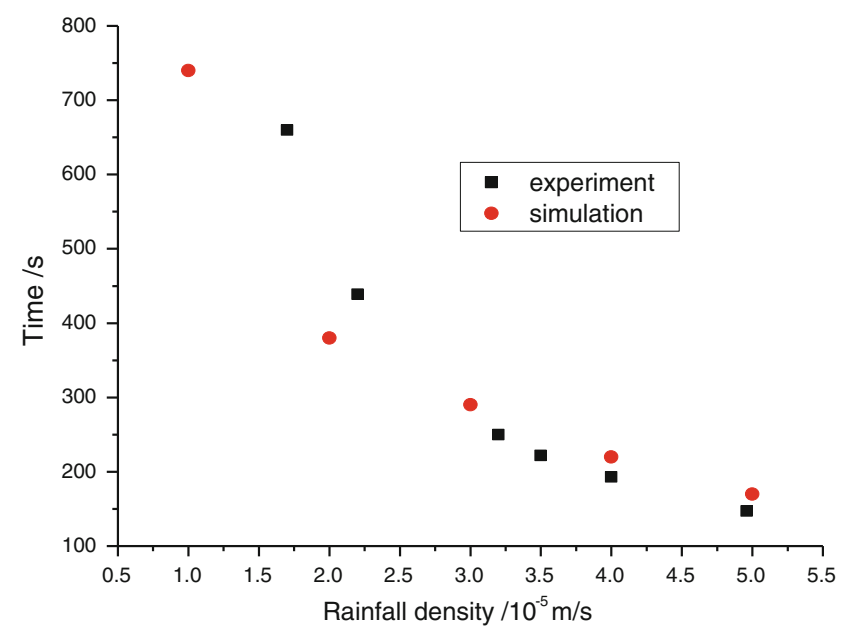

Fig. 75.8 Debris flow initiation time versus the rainfall duration

\subsection{Conclusions}

The conclusions are as follows:

Under rainfall conditions, the maximum horizontal displacement occurs at the foot of the slope and increases with the rainfall duration, the vertical displacement is non-uniform and the maximum value occurs at a point of two-third slope from the top of the slope. When rainfall lasts a period of time, the horizontal displacement has a sudden change. The vertical non-uniform displacement is mainly resulted by the horizontal movement of soil, and it leads to a weak point for the initiation of debris flow.

Under rainfall conditions, the velocity vector of soil increases with the rainfall duration, the maximum component in vertical direction occurs at a point of two-third slope from the top of slope, and the maximum ones in horizontal direction occurs at the foot of the slope. The horizontal movement of soil plays a key role during the initiation of debris flow.

The sudden change in displacement at characteristic point is used as a criterion to judge the initiation of debris flow. There is a good agreement between the numerical simulation results and the laboratory test ones.

Acknowledgments This study is supported by National Basic Research Program of China "activity characteristics and formation rules of secondary mountain hazard of earthquake" (No. 2008CB425802).

\section{References}

Chen S (1997) A method of stability analysis taken effects of infiltration and evaporation into consideration for soil slopes. Rock Soil Mech 18(2):8-12

Chen X, Sun H (2007) Saturated-unsaturated seepage analysis of slope under rainfall. Sci Technol Eng 7(24):115-118

Gong B, Ng CWW, Bao C et al (2002) Field study of the effects of rainfall infiltration on channel slope of expansive soil. J Yangtze River Sci Res Inst 19:95-97

Iverson RM (1997) The physics of debris-flows. Rev Geophys 35 (3):245-296

Iverson RM, Reid ME, LaHusen RG (1997) Debris-flow mobilization from landslides. Annu Rev Earth Planet Sci 25:85-138

Iverson RM et al (1989) Dynamic pore-pressure fluctuations in rapidly shearing granular materials. Science 246:796-799

Li Z, Zhang M (2001) Effects of rain infiltration on transient safety of unsaturated soil slope. J Civil Eng 34(5):57-61

Liu Y (1998) Critical precipitation of rainstorm for landslide. Hydrogeol Eng Geol 3:43-45

Luo W, Yan T (1995) A tentative research into dynamic effects of rain and groundwater on slope stability. Geol Sci Technol Inf 14(4):7781

Major JJ, Iverson RM (1999) Debris-flow deposition: effects of porefluid pressure and friction concentrated at flow margins. Geol Soc Am Bull 111(10):1424-1434

Qin G, Huang R (2003) Study on genetic and mechanical analysis of debris flow based on unsaturated soils mechanics. Chin J Geol Hazard Control 14(3):4-9

Richards LA (1931) Capillary conduction of liquids through porous mediums. Physics 1:318-333

Sun Y, Nishigaki M, Kohno I (1995) A study on stability analysis of shallow layer slope due to raining permeation. In: Proceedings of the 1st international conference on unsaturated soils. Rotterdam Balkema, pp 1135-1141

Sun Y, Sakajo S, Nishimura M (1997) Application research on a numerical model of two-phase flow in deformation porous medium. Int Conf Comput Method Adv Geomech Wuhan II:1171-1176

Xie S, Xu W (1999) Mechanism of landslides induced by precipitation. J Wuhan Univ Hydraul Electr Eng 32(1):21-23

Xu Z, Yang L (2000) A simulation of the hydraulic and mechanical response to the rainfall process of typical subgrade slope in Chendu Chongqing railway. J Southwest Jiaotong Univ 35(1):80-81

Yao HL, Zheng SH, Chen SY (2001) Analysis on the slope stability of expansive soil considering cracks and infiltration of rain. Chin J Geotech Eng 23(5):606-609

Zhu W, Liu B (2002) Forming and development process of soil landslide during rainfall. Chin J Rock Mech Eng 21(4):509-512 